\title{
O CUIDADO DE SI COMO CONDIÇÃO PARA O CUIDADO DOS OUTROS NA PRÁTICA DE SAÚDE
}

\author{
Valéria Lerch Lunardi ${ }^{1}$ \\ Wilson Danilo Lunardi Filho ${ }^{2}$ \\ Rosemary Silva da Silveira ${ }^{3}$ \\ Narciso Vieira Soares ${ }^{4}$ \\ Jussara Mendes Lipinski ${ }^{4}$
}

Lunardi VL, Lunardi WD Filho, Silveira RS, Soares NV, Lipinski JM. O cuidado de si como condição para o cuidado dos outros na prática de saúde. Rev Latino-am Enfermagem 2004 novembro-dezembro; 12(6):933-9.

É necessário olhar criticamente para as nossas práticas e para as relações que estabelecemos em nossa vida pessoal e profissional, para termos um viver pautado na ética. Neste texto, problematizamos práticas de governabilidade, construídas nas relações que os profissionais de saúde e, em especial, os enfermeiros estabelecem entre si, com as instituições de saúde e com os clientes e na relação com a profissão. Concluímos que, para alguém cuidar do outro e conduzi-lo, como o fazem os enfermeiros em suas práticas, primeiramente necessita demonstrar que podem conduzir-se, que conhece os limites de sua prática e que necessita respeitar o outro como alguém diferente de si próprio.

DESCRITORES: enfermagem; poder(psicologia); ética; autonomia pessoal

\section{SELF CARE AS A CONDITION FOR CARE TO OTHERS IN HEALTH PRACTICE}

We need to take a critical look at our practices and the relationships we construct in our personal and professional life, with a view to leading a life guided by ethics. In this text, we discuss governability practices that are built in the relations between health and especially nursing professionals, with the health institutions, with the clients and with the nursing profession. We conclude that, for persons to deliver care and guide others, like nurses do in their practice, they first need to demonstrate that they can guide themselves, that they know the limits of their practice and can respect the other as someone different from themselves.

DESCRIPTORS: nursing; power (psychology); ethics; personal autonomy

\section{EL CUIDADO DE SÍ COMO LA CONDICIÓN PARA EL CUIDADO DE LOS OTROS EN LA PRÁCTICA DE SALUD}

Es necesario dirigir una mirada crítica para nuestras prácticas y relaciones que establecemos en la vida personal y profesional para tenermos un vivir ético. En este texto, discutimos prácticas de gobernabilidad construidas en relaciones que los profesionales de salud y los enfermeros en especial establecen entre sí, con las instituciones de salud, con los clientes y con la profesión. Es posible concluir que, para alguien cuidar y conducir el otro, como lo hacen los enfermeros en sus prácticas, primeramente necesitan demostrar que pueden conducir a sí mismos, que conocen los límites de su práctica y que pueden respetar al otro como alguien diferente de sí propios.

DESCRIPTORES: enfermería; poder (psicología); ética; autonomía personal

\footnotetext{
${ }^{1}$ Doutor em Enfermagem, Docente da Fundação Universidade Federal do Rio Grande, Pesquisador CNPq, e-mail: vlunardi@terra.com.br; ${ }^{2}$ Doutor em Enfermagem, Docente da Fundação Universidade Federal do Rio Grande; ${ }^{3}$ Mestre em Enfermagem, Doutoranda, Enfermeira do Hospital Universitário Dr. Miguel Riet Corrêa; ${ }^{4}$ Mestre em Enfermagem, Docente da Universidade Regional Integrada do Alto Uruguai e das Missões Campus de Santo Ângelo
} 
INTRODUÇÃO

$\boldsymbol{A}$ ética, a partir dos gregos, é entendida, para Foucault, como "a prática da liberdade, a prática reflexiva da liberdade" ${ }^{\prime(1)}$. Para nos conduzirmos adequadamente nas relações, para exercermos a liberdade como devemos, é preciso ocupar-nos de nós, cuidamos de nós; não numa perspectiva de egoísmo ou de interesse individual, mas como aperfeiçoamento pessoal, superação dos apetites, dos desejos e paixões que possam dominar-nos. Ou seja, cuidar de si significa, antes de tudo, não ser escravo: dos outros, dos que nos governam, como de nós próprios, das nossas próprias paixões ${ }^{(1)}$.

Assim, quando falamos em governabilidade, seja de si, seja do outro, a preocupação com a liberdade tornase essencial, e daí a questão ética, apontada por Foucault: "para que este exercício da liberdade assuma a forma de um ethos belo, bom, honorável e que possa servir de exemplo, é necessário todo um trabalho do sujeito sobre si mesmo"(1). Numa perspectiva foucaultiana, a liberdade, então, é essencialmente política, na medida em que "ser livre significa não ser escravo nem de si mesmo (...) exercendo sobre si uma relação de domínio (...) poder, mando"(1). Quem cuida de modo adequado de si mesmo, encontra-se em condições de relacionar-se, de conduzirse adequadamente na relação com os demais ${ }^{(1)}$.

Assim, como profissionais de saúde, podemos nos perguntar: como vem se produzindo a nossa construção e formação moral? Predominantemente, nós nos construímos pautados por uma moral autônoma, em que nos permitimos questionar, duvidar e, se necessário, provocar mudanças, romper com o instituído? Ou, fundamentalmente, agimos a partir do que outros decidem e determinam que façamos, apesar do sofrimento provocado, do sentimento de inadequação, e da possível culpa resultante do conflito entre o que acreditamos que devemos fazer e o que, na verdade, aceitamos ou nos sujeitamos fazer? Tais questões relacionam-se com a governabilidade: como os profissionais de saúde vêm se governando? Como vêm se deixando governar? Como vêm governando aos outros?

Nas instituições de saúde, por diferentes caminhos, vem-se demonstrando, cada vez mais, que determinados modos adotados de ser e de fazer não apenas comprometem e prejudicam os profissionais, como, principalmente, comprometem o que se chama de cuidado aos clientes, a sua assistência à saúde.
Neste texto, pretendemos enfocar um agir ético na área da saúde, em especial na enfermagem, a partir da relação do profissional consigo mesmo, pautando-se em valores, como o respeito à vida e ao ser humano, mas também articulado à relação com a profissão que exercemos, com as instituições nas quais atuamos, com os colegas trabalhadores e, por último, à ética nas relações com os clientes assistidos e cuidados, seja o indivíduo, sua família e/ou grupos sociais. Abordaremos questões mais gerais das nossas relações com a profissão, com as instituições, com as equipes de trabalho, tendo em vista que podem estar presentes no dia a dia do trabalho do profissional comprometido com as diferentes pessoas, especialmente no que se refere a sua saúde.

\section{A ÉTICA NA RELAÇÃO COM A PROFISSÃO}

Na relação com a profissão, como uma prática social, há legislações específicas, como na enfermagem, que dispõem sobre o exercício profissional ${ }^{(2-3)}$, estabelecendo o que é da competência de cada profissional e, dentre estas competências, o que é privativo do enfermeiro, o que não pode ser delegado, garantindo o desenvolvimento da área de enfermagem, o aprimoramento de saberes da profissão, a realização profissional, mas mais do que isso, a qualidade da assistência aos clientes. A relevância e necessidade de incorporação da sistematização da assistência de enfermagem à prática é destacada, concretizando o determinado pela legislação profissional $^{(4)}$. Há, ainda, decisões que estabelecem o que são cuidados de enfermagem complexos, privativos do enfermeiro, assim como o que compete aos técnicos de enfermagem e aos auxiliares de enfermagem ${ }^{(5)}$. O próprio código de ética profissional explicita, como uma prescrição moral, os princípios fundamentais da profissão, os direitos dos trabalhadores, suas responsabilidades, deveres e proibições $^{(6)}$.

Buscar condições para que cada profissional assuma o que é de sua competência legal, argumentar com as chefias e administrações quanto à necessidade de recursos humanos é um compromisso com a profissão e com a comunidade que solicita nossos serviços, assim como conosco, com a nossa formação e qualificação. Ainda, mais difícil do que o convencimento de chefias e administrações, pode ser o convencimento do próprio enfermeiro acerca da necessidade de assumir 
determinadas práticas que lhe dão identidade e a profissão que exerce, como a prescrição da assistência de enfermagem. Por que nós, enfermeiros, freqüentemente, relegamos o nosso saber e fazer específico e privativo, cuja aplicação provocaria ou aceleraria o desenvolvimento científico da profissão, em detrimento de fazeres dependentes, os quais poderiam ser delegados a outros profissionais da equipe de enfermagem ou sequer ser assumidos pela enfermagem?

\section{A ÉTICA NA RELAÇÃO COM A INSTITUIÇÃO}

Na relação com a instituição, podemos referir-nos a como se organiza o trabalho quanto aos recursos humanos e materiais. Freqüentemente, em algumas instituições, os trabalhadores se vêem na contingência de ter que atuar com recursos materiais, em condições inadequadas de funcionamento, de qualidade questionável, insuficientes, expondo a biossegurança dos trabalhadores, dos clientes, a falta de privacidade e intimidade diante da organização do ambiente de enfermarias, dentre outros elementos que poderiam ser apontados. Como cuidar adequadamente do outro, se quem se reconhece como cuidador é desrespeitado e permite que seu saber seja desrespeitado no que se refere às necessidades materiais do ambiente de trabalho?

Aquino, Araujo, Menezes, Marinho; Enders; Lunardi; Lunardi Filho; Mendes, Trevisan, Lourenço; Santos, Rodrigues Filho denunciam a contradição existente entre uma visão idealizada da profissão e as condições de trabalho enfrentadas: a baixa remuneração, o trabalho excessivo, o trabalho por turnos, a precariedade de recursos materiais e a insuficiência de recursos humanos, a insegurança no trabalho, o trabalho com a doença e a morte ${ }^{(7-12)}$; as dificuldades comunicacionais e de relacionamento da equipe de enfermagem e com a equipe médica ${ }^{(13)}$. No entanto, o temor de perder o emprego ainda tem levado os enfermeiros a se submeterem às determinações da organização ${ }^{(14)}$, negando não apenas a si, mas possivelmente comprometendo o cuidado dos clientes.

\section{A ÉTICA NA RELAÇÃO COM A EQUIPE}

A interação de nossas práticas com os princípios da bioética (beneficência, não maleficência, autonomia e justiça) pode ser demonstrada, seja pela sua aproximação, seja pelo seu desrespeito. A transgressão dos princípios bioéticos decorre, fundamentalmente, da representação de um agir ético da enfermagem, semelhante à atuação do que foi denominado por Selli como a da 'mãe da casa', que pretende, de um modo até onipotente e, aparentemente, sem pensar e refletir, 'vigiar', 'dar conta' e responsabilizar-se por tudo: pelo paciente, como se pudéssemos ser o seu dono e donos, também, do seu corpo; pelo exercício de proteção ao médico como se esse profissional precisasse de uma mãe que o defendesse; pela instituição e seu funcionamento como um todo ${ }^{(15)}$.

Esse modo histórico, tradicional, reprodutivo e mecânico de agir tem feito com que a enfermagem se perca, por vezes, nos meios, sem conseguir alcançar os fins que diz pretender: o cuidado do cliente como pessoa. Para a equipe de enfermagem reconhecer no paciente um ser humano, e assim cuidá-lo, precisa, também, e num estágio anterior, reconhecer-se e tratar-se como um ser humano ${ }^{(16-17)}$. O cuidado dos elementos da equipe como sujeitos que necessitam exercer o seu cuidado para assegurar o cuidado dos outros, há anos vem sendo enfatizado ${ }^{(16)}$. O cuidado de si constitui-se em parar, dirigir o nosso olhar para a nossa vida, permitir-nos realizar um exame de consciência sobre o vivido, não para julgá-lo, nem para culpar-nos, mas para perguntar-nos sobre as intenções propostas e não alcançadas, sobre como vimos administrando nossa existência, a nós mesmos, como um bem a ser preservado ${ }^{(1)}$. Como vimos aplicando, na nossa prática, valores e princípios que tão ferrenhamente defendíamos, criticando quem os transgredia?

Freqüentemente, deparamo-nos com situações que poderiam ser caracterizadas como dilemáticas, conflituosas, de enfrentamento de relações de poder, em que nos perguntamos se devemos ficar calados ou falar, omitir-nos ou agir, participar ou ficarmos indiferentes. Qual o caminho a seguir? Quem vem sendo prejudicado com o nosso fazer? Quem vem sendo beneficiado como o nosso modo de ser? Qual a justificativa moral para o nosso modo de agir?

A identificação e o reconhecimento de uma situação dilemática pode ser entendida como um passo importante na nossa constituição como sujeitos éticos, pois muitos de nós sequer percebemos, em muitas situações do cotidiano, conflitos, problemas ou dúvidas. Existe uma dupla cegueira: não conseguimos sequer 
enxergar que não enxergamos. Problematizar o cotidiano vivido, perceber problemas, dificuldades, contradições, questionamentos, é o primeiro passo para falarmos em ética.

Assim, frente aos recursos humanos de que dispomos, qual o número necessário de trabalhadores para cuidar de quem, aparentemente, confia na instituição que buscou; qual a formação dos profissionais para exercer o que lhes cabe? Há quanto tempo não participam de atividades de educação em serviço, de reciclagem e atualização? Como vêm cuidando dos clientes? Que relações estabelecem com os clientes: predominantemente pautadas pela horizontalidade, respeito, autonomia, compromisso, solidariedade? Diante de evidências de desrespeito, qual tem sido a conduta profissional? O silêncio, a omissão, a indiferença? A opção por uma ética corporativa que nada tem de ética porque vai contra os direitos do cliente, de ser respeitado, consultado, ouvido e contra o dever profissional de não ser conivente com situações de transgressão e imorais? Porém, como enfrentar tais situações? Daí, a necessidade da busca de ajuda, de parar, pensar, constituir grupos de discussão, da participação das comissões de ética, do estranhamento de situações que, com o passar do tempo, podem se mostrar naturais e normais, porém não o são.

\section{A ÉTICA NA RELAÇÃO COM O CLIENTE}

E como vem se dando a ética na relação com os clientes? Poderíamos iniciar com a necessidade de solicitação de seu consentimento livre e esclarecido, ou de seus responsáveis, para a realização de procedimentos, mesmo aqueles entendidos por nós, como necessários. Se o cliente é um sujeito e não um objeto de cuidado, tem o direito de ser informado do que lhe está acontecendo, de ser informado dos seus direitos, o que significa ter atitudes e ações de respeito, de diálogo, de ser consultado, de participar de decisões que lhe dizem respeito, a partir de esclarecimentos numa linguagem clara, simples e acessível, reconhecendo sua capacidade de pensar e, principalmente, de divergir das nossas crenças, valores e propósitos.

O conhecimento do cliente é fundamental para que alcance a independência e a autonomia no seu cuidado. A sua independência é um princípio na nossa ação e uma meta a ser permanentemente buscada: o preparo para o seu próprio cuidado, de modo mais autônomo possível. Na década de oitenta, já era apontada a necesidade de retomar a concepção de autocuidado, mais aceita e difundida em países desenvolvidos quanto aos seus princípios e aplicabilidade, considerando o contexto brasileiro ${ }^{(18)}$. Era denunciado que, na assistência de enfermagem, o enfermeiro ainda estava assumindo 0 papel de sujeito do processo, decidindo como atuar, dirigindo as suas ações e as dos clientes, tomando como fundamento os problemas que ele considerava prioritários, o que pressupunha uma relação assimétrica e de desigualdade, uma realidade que ainda necessitava ser superada. Assim, para que a pessoa pudesse decidir sobre sua saúde e se cuidar, era entendido ser fundamental que estivesse mobilizada a utilizar sua própria consciência crítica. Como refere Noronha, "o trabalho 'com' é diferente do trabalho 'para' ou 'pelo' cliente. (...) uma das premissas do autocuidado é a decisão e, em tese, qualquer pessoa em lucidez pode decidir e raciocinar acerca do seu corpo, seus interesses, seu próprio bem-estar e o da coletividade. (...) a decisão, a liberdade e participação que são os pontos fundamentais para o desempenho do autocuidado constituem direitos inalienáveis das pessoas, e o impedimento da satisfação dessas necessidades só acontece em circunstâncias extremas"(18).

Talvez seja pertinente voltar a questionar: qual tem sido, fundamentalmente, o papel do cliente no processo da assistência e, principalmente, nas tentativas de implementação do autocuidado? Apesar de os discursos sobre o autocuidado reforçarem a participação do cliente no seu cuidado ou no planejamento da sua assistência, a percepção e a abordagem do cliente enquanto um sujeito capaz de pensar, de refletir, de conhecer e de optar, decidindo por si e para si o que é o melhor, como um ser dotado de razão, de vontade e de capacidade de exercer sua liberdade, parece ainda não se fazer de modo satisfatório, já que o sujeito que determina o processo parece ainda ser o profissional de saúde. Uma questão poderia ser colocada acerca do que é prioritário para os profissionais de saúde: o cliente ou o seu tratamento, o cliente ou a sua saúde, principalmente, frente a manifestações ainda identificadas de que é importante a sua participação no seu tratamento, mas que a sua capacidade de opção deve ser considerada e respeitada e/ou suas solicitações devem ser atendidas na medida em que não vierem prejudicar ou comprometer o seu tratamento. 
Como profissionais da saúde, parece que, na prática do dia-a-dia, a prioridade da equipe de saúde, fundamentalmente, tem sido o que entendemos como a manutenção e recuperação da saúde dos clientes. Essa busca da saúde tem se concretizado por meio da implementação de um programa ou de um tratamento reconhecido como a resposta e a solução para os clientes e, muitas vezes, independente do que eles, como pessoas, pensem, sintam, acreditem, prefiram e desejem. Nesse embate, uma pergunta que retorna é: quem tem sido reconhecido como sujeito e quem tem sido reconhecido como objeto em tais relações?

Por outro lado, o resgate de situações vivenciadas não tem a intenção de, apenas, efetivar uma crítica sobre como se tem feito a prática, na saúde, da enfermagem e a sua governabilidade. A intenção é problematizar uma prática, na qual, como enfermeiros, nos inserimos, na tentativa de propor e reforçar um estranhamento sobre um cotidiano que possa estar sendo percebido, vivido e valorizado como normal e, quem sabe, como inquestionável e permanente. Muitas dessas ações podem estar sendo reconhecidas como morais e/ou eticamente aceitáveis, requerendo, então, que participemos de um processo de afastamento e desnaturalização ${ }^{(19)}$, como exigência prévia para sua posterior modificação e transformação.

Assim, podemos observar pessoas que realizam exames preventivos de câncer e são encaminhadas para novos exames, como uma colposcopia, sem serem informadas sobre o processo patológico vivido, sem conhecimento do seu significado, da possível gravidade e da necessidade urgente de procurar os serviços para os quais foram encaminhadas, retornando, muitas vezes, quando o processo mórbido está bastante avançado ${ }^{(20)}$. Outras vão marcar sua cirurgia, desconhecendo totalmente seu diagnóstico e, até, a cirurgia a que vão se submeter ${ }^{(21)}$; há o desconhecimento da necessidade de extirpação de uma mama até poucas horas antes da cirurgia ou tomam ciência da extirpação após sua ocorrência ou, ainda, a falta de participação das mulheres no processo de tomada de decisão sobre o tratamento do câncer de mama ${ }^{(22)}$; o desconhecimento da necessidade do uso de uma bolsa de colostomia até recuperar-se da anestesia; assim como o desconhecimento dos efeitos colaterais da quimioterapia ${ }^{(23)}$. Esses são apenas alguns exemplos de transgressões encontradas na bibliografia e na vida real das instituições de saúde.
Um aspecto que poderia ser discutido, refere-se a quem, na equipe de saúde, cabe orientar os clientes quanto ao seu diagnóstico, tratamento e cuidados, assim como a discussão acerca do direito de o cliente, já informado, ter a opção de checar um diagnóstico, de discutir possibilidades de tratamento, suas conseqüências, seus diferentes efeitos colaterais previstos, para, então, decidir como agir. Embora a responsabilidade da comunicação do diagnóstico seja do profissional médico ${ }^{(24)}$, a enfermagem tem um papel importante de colaboração e apoio nessas situações. Especificamente qual a nossa responsabilidade frente à constatação de ignorância dos clientes quanto a qualquer procedimento diagnóstico e/ou terapêutico a que vão se submeter? Tão importante quanto esclarecer o cliente acerca do seu diagnóstico, é a decisão de como informá-lo, considerando sua história, valores e sentimentos, em que a comunicação de seu diagnóstico é apenas a concretização de um meio para que esse cliente possa ser reconhecido, reconhecer-se e fortalecer-se como sujeito de si.

O enfrentamento do esclarecimento de um diagnóstico requer uma relação de solidariedade que pode ser entendida como uma relação de crescimento mútuo, entre pares, que buscam tornar-se mais sujeitos na busca e na apreensão da verdade. O problema da informação de um diagnóstico, freqüentemente associado à morte, e negado, comumente, tanto pela equipe de saúde como pela família, poderia estar associado à dificuldade existente entre as pessoas, de um modo geral, e também dos profissionais de saúde de enfrentarem o tema da morte. Parece preferível deixar velado e na escuridão um assunto que nos sentimos despreparados para enfrentar, optando por desconsiderar e negar a possibilidade de o cliente ser tratado como uma pessoa que pode estar enfrentando uma situação de morte e que tem o direito de ser respeitada, nessa situação, como pessoa, 'dona da sua vida'.

Estamos mais preparados, aparentemente, para trabalhar com a vida do que com as suas possibilidades de interrupção e morte. Não será necessário conhecermos e trabalharmos nossos sentimentos, crenças, temores frente à morte para enfrentarmos situações que possam ter esse significado? Como cuidar do outro, talvez, vivenciando um processo que tenha a morte como significado sem, anteriormente, ocupar-nos de nós, voltarnos para nós, para conhecer-nos e preparar-nos para o nosso próprio processo de morte? Como cuidar de 
pessoas com diagnósticos que possam ter o significado de morte, sem que nos perguntemos, antes, o que significam tais diagnósticos para nós; sem que, antes, nos preparemos para cuidar delas? Será possível dizer que somos cuidadores se nossa relação com o cliente se faz apenas com o seu corpo, um corpo que pode requerer uma aspiração, uma medicação, um banho, porém evitamos reconhecer nele uma pessoa que quer falar, ser ouvida e tocada como gente, como mais do que um corpo sadio ou doente?

\section{CONSIDERAÇÕES FINAIS}

Para finalizar, consideramos que o exercício da crítica não somente aos outros, mas fundamentalmente a nós, ao modo como temos nos cuidado, regido nossa vida e possibilitado que outros a dirijam, ao modo como

\section{REFERÊNCIAS BIBLIOGRÁFICAS}

1. Foucault M. Hermenéutica del sujeto. Madrid: La Piqueta; 1987.

2. Lei do Exercíco Profissional $n^{0} 7498$ de 25 de junho de 1986. Dispõe sobre a regulamentação do exercício da enfermagem e dá outras providências. Diário Oficial da União 1986. 26 junho, seção I, p.9273-5.

3. Lei $n^{\circ} 8967$ de 28 de dezembro de 1994. Altera a redação do parágrafo único do art. 23 da Lei $n^{0} 7.498$, de 25 de junho de 1986. Dispõe sobre a regulamentação do exercício da enfermagem e dá outras providências. Lex: coletânea de legislação e jurisprudências, 1994. dezembro, 58, p. 1756. 4. Resolução COFEN n² 272/2002 de 27 de agosto de 2002. Dispõe sobre a Sistematização da Assistência de Enfermagem - SAE - nas Instituições de Saúde. [online]. [acessado 06 junho 2004]. Disponível em: URL: http:// www.corensp.org.br/resolucoes/resolucoes.html

5. Decisão COREN/RS n ${ }^{\circ} 103 / 00$ de 27 de setembro de 2000. Dispõe sobre a normatização das atribuições dos profissionais de enfermagem. [Conselho Regional de Enfermagem do Rio Grande do Sul. Legislação]. Porto Alegre (RS): 2001. p. 49-53.

6. Resolução COFEN n² 240/2000 de 30 de agosto de 2000. Aprova o Código de Ética dos Profissionais de Enfermagem. Conselho Regional de Enfermagem do Rio Grande do Sul. Legislação. Porto Alegre (RS): 2001. p.31.

7. Aquino EML, Araújo MJS, Menezes GMS, Marinho LFB. Saúde e trabalho de mulheres profissionais de enfermagem em um hospital público de Salvador. Rev Bras Enfermagem 1993 julho/dezembro; 46(3/4):245-57.

8. Enders BC. O papel do enfermeiro de saúde pública: projeções no ensino. Rev Bras Enfermagem 1993 julho/ dezembro; 46(3/4):266-70.

9. Lunardi VL. Fios visíveis/invisíveis no processo educativo de (des)construção do sujeito enfermeira. [dissertação]. Porto Alegre (RS): Faculdade de Educação/UFRGS; 1994. temos nos relacionado com os outros, é imprescindível para que mudemos nossa forma de ser, convertendo-nos no que não éramos ${ }^{(18)}$. Como podemos ser dirigentes de um grupo, de uma equipe, se sequer conseguimos dirigir a nós próprios? Aquele que pretende cuidar dos outros e dirigi-los (e nós, profissionais de saúde, comumente estamos nessa situação), antes de tudo, necessita demonstrar que sabe dirigir a si próprio, que conhece os limites do seu fazer, que respeita o outro como um ser diferente de si.

Acreditamos que, à medida que exigirmos, de nós mesmos, a liberdade de pensarmos como exercemos nosso fazer profissional, na tentativa de entender por que temos assumido um modo de ser, possamos não refutar o que somos ou a realidade em que estamos imersos, mas encontrar alguns caminhos que favoreçam o exercício de práticas de cuidado pessoal, de transformação de nós mesmos, dos outros, e da sociedade.

10. Lunardi WD Filho. Prazer e sofrimento no trabalho: contribuições à organização do processo de trabalho da enfermagem. [dissertação]. Porto Alegre (RS): Escola de Administração/UFRGS; 1995.

11. Lunardi WD Filho. O mito da subalternidade do trabalho da enfermagem à medicina. [tese]. Florianópolis (SC): Programa de Pós-Graduação em Enfermagem/UFSC; 1998. 12. Mendes IAC, Trevisan MA, Lourenço MR. La gerencia aclarada en el trabajo del enfermero. Rev Latino-am Enfermagem 2002 setembro-outubro; 10(5):704-8.

13. Royas AV, Marziale MHP. A situação de trabalho do pessoal de enfermagem no contexto de um hospital argentino: um estudo sob a ótica da ergonomia. Rev Latino-am Enfermagem 2001 janeiro; 9(1):102-8.

14. Santos SR, Rodrigues JR Filho. Enfermagem: fatores de satisfação. Rev Bras Enfermagem 1995 julho/setembro; 48(3):242-50.

15. Selli L. Beneficência, autonomia e justiça como princípios bioéticos: implicações para o fazer da enfermagem. [dissertação]. Florianópolis (SC): Programa de PósGraduação em Enfermagem/UFSC; 1997.

16. Rockenbach LH. A enfermagem e a humanização do paciente. Rev Bras Enfermagem 1985 janeiro/ fevereiro; 38(1):49-54.

17. Esperidião E, Munari DB, Stacciarini JMR. Desenvolvendo pessoas: estratégias didáticas para o autoconhecimento na formação do enfermeiro. Rev Latino-am Enfermagem 2002 julho/agosto; 10(4):516-22.

18. Noronha R. Experiência participativa mobilizadora de enfermagem - condições prévias para o auto-cuidado. Rev Bras Enfermagem 1986 janeiro/março; 39(1):34-43.

19. Foucault M. A história da sexualidade II: O uso dos prazeres. Rio de Janeiro (RJ): Graal; 1984.

20. Chiesa AM. Assistência à saúde das mulheres do município de Taboão da Serra com diagnóstico de displasia ou carcinoma cérvico-uterino: problematização no sistema de referência e contra-referência. Rev Bras Enfermagem 1992 janeiro/março; 45(1):28-35. 
21. Maia CAT, Colodo M, Vale IN. Cirurgia ginecológica: trabalho em grupo visando o preparo para internação. Rev Bras Enfermagem 1988 janeiro/março; 41(1):34-8.

22. Arantes SI, Mamede MV. A participação das mulheres com câncer de mama na escolha do tratamento: um direito a ser conquistado. Rev Latino-am Enfermagem 2003 janeirofevereiro; 11(1):49-58.

23. Fialho AVM, Silva RM. Mastectomia e suas repercussões. Rev Bras Enfermagem 1992 janeiro/março; 45(1):28-35.

24. Resolução n 1246. Aprova o Código de Ética Médica. Diário Oficial da União 1988. 26 janeiro, seção I, p.1574-7. 